\title{
TOXICITY STUDIES OF DRUGS AND CHEMICALS IN ANIMALS: AN OVERVIEW
}

\author{
S. A. SAGANUWAN \\ Department of Veterinary Physiology, Pharmacology and Biochemistry, \\ College of Veterinary Medicine, University of Agriculture, Makurdi, \\ Benue State, Nigeria
}

\section{Summary}

Saganuwan, S. A., 2017. Toxicity studies of drugs and chemicals in animals: An overview. Bulg. J. Vet. Med., 20, No 4, 291-318.

Toxicity study is the investigation of either short or long-term toxic effects of a drug or chemical on animals. The toxicity is dose-dependent as asserted by Paracelsus over 500 years ago. However, short-term toxic effect is determined using median lethal dose $\left(\mathrm{LD}_{50}\right)$ first introduced by Trevan in 1927 and revised many times. Presently there is a growing preponderance of rejection of scientific papers on acute toxicity study, simply because of the belief that in the current hazard and safety assessment of drugs and chemicals, $\mathrm{LD}_{50}$ values are no longer used. In view of this, literature search was carried out with a view to investigating the relevance of $\mathrm{LD}_{50}$ in development and assessment of drugs and chemicals. The findings revealed that in the past, many animals had been used for $\mathrm{LD}_{50}$ determination. OECD has reduced the number of test animals to 5-15 and presently it is further reduced to 2-6. Acute toxicity study is being carried out in medicinal plants research and in the study of patent medicine. Although the application of $\mathrm{LD}_{50}$ has been drastically reduced, it is still applied and accepted in some parts of the world. Moreover, animals on which $\mathrm{LD}_{50}$ tests are conducted, should be allowed to die to see the end effect of the test drug or chemical because euthanisia of test animals may mask some toxicity signs of the test agents. Therefore, toxicity study of drugs and chemicals is a scientific process necessary for discovery and development of drugs as well as identification of potential toxicants.

Key words: median lethal dose, Paracelsus, therapeutic agent, toxicant, toxicity

\section{INTRODUCTION}

Attempts have been made to see whether the chemical structure of the molecule itself may serve as a predictor of toxic or carcinogenic effects (Golberg, 1983; Rosenkranz et al., 1999). Such predictions are often based on particular active sites, such as the number of aromatic rings in polycyclic hydrocarbons or the number of chlorine atoms in chlorinated hydrocarbons. Such classification had some success but is far from perfect (Goddard et al., 1996). Nevertheless, Paracelsus asserted that toxicity effects of toxicants and therapeutic agents are dose-dependent 
(Castleman, 2002). In that regard, Trevan introduced the concept of the median lethal dose $\left(\mathrm{LD}_{50}\right)$ in 1927. Median lethal dose is the amount of test agent that can causes death in $50 \%$ of test animals. There are different methods used to estimate median lethal dose (Karber, 1931; Reed \& Muench, 1938; Miller \& Tainter, 1944; Litchfield \& Wilcoxon, 1949; Lorke, 1983; ASTM, 1987; Dixon, 1991; Saganuwan, 2011; Saganuwan et al., 2011; Saganuwan \& Onyeyili, 2016). Earlier methods adopted for the estimation of median lethal dose used many animals (40-100), but for up-and-down procedure, 4-15 animals can be used (OECD, 1987; 2000a,b; 2001a,b,c; Stitzel, 2000; UNECE, 2003). Saganuwan (2014) revised the up-and-down procedure (UDP) to the use of 2-6 animals that may likely give 1-3 reversals. If there is no death above $15,000 \mathrm{mg} / \mathrm{kg}$ body weight, the test agent is practically safe and that serves as the limit boundary. The revised method saves time, reserves large numbers of animals that may be wasted and ignores complex mathematical manipulation involved (Saganuwan, 2014). The method is faster and its findings are relatively comparable to the findings with other methods (Saganuwan, 2012). For all the methods, the study outcome is likely to be influenced by the choice of starting dose level(s) relative to the true $\mathrm{LD}_{50}$ value, especially in the case of shallow slopes (Gribaldo et al., 2005). Therefore, information on toxic effects seen only at dose levels close to a lethal dose will not be obtained (Van der Heuvel et al., 1990). However, the dangerous dose for humans may be $1-100 \%$ more or less of the determined $\mathrm{LD}_{50}$ (Dreisbach \& Robertson, 1987). Because small numbers of animals were used, the actual level of confidence is generally not exact (Jennison \&
Turnbull, 2000). The random stopping rule in UDP improves the overall ability of the test to respond to varying underlying conditions, but also causes the reported level of confidence and the actual level of confidence to differ somewhat (Botham, 2003). Of all the principles of the three alternatives (fixed dose; acute toxic class and up-and-down), up-anddown is the most suitable, because it gives end-point-evidence toxicity and obeys stopping criteria to limit number of animals used, using only 2-6 animals with possible 1-3 deaths (Shiryaev \& Spokoing, 2000).

\section{HISTORICAL BASIS OF TOXICITY STUDIES}

Roman herbalists were as likely to be killers as healers. As a result, throughout the Roman Empire herbalists became obsessed with the identification of herbal poisons and the development of antidotes known as theriaca (in Greek meaning remedies for venomous bites). The ancient world's most poison-paranoid ruler was Mithridates Eupalor (120-60 B.C.), king of Pontus, on the Black Sea. He took increasing doses of poisons to develop a tolerance and make himself immune. In 66 B.C., Romans attacked him, he attempted to poison himself but he has become tolerant and finally ordered a slave to stab him to death to escape embarrassment from enemies (Castleman, 2002). The bubonic plague caused by Yersinia pestis and spread by rat flea, Xenopsylla cheopis probably began in Asia in the year 1330, spreading to Norht Africa, Europe and the Middle East. This epidemic caused 25 to $33 \%$ drop in population of Europe between 1330 and 1350. Programmes were launched against the Jews of Europe, who were thought responsible for the epi- 
demic, even though the pope pointed out the ludicrousness of this belief (Stolley, 1995). The bubonic plague caused by Yersinia pestis toxin ravaged Europe for many centuries although at the International Medical Congress in Berlin, 1890, Robert Koch reminded his contemporaries that so-called vibroids seen in anthrax and relapsing fever are the cause of these diseases (Moxon, 1990). The most vocal champion of the Doctrine of signative was Phillippus Aureolus Theophrastus Bombastus Von Hohenheim (1493-1541 A.D.), the founder of toxicology, the son of a Swiss alchemist/physician. A brilliant arrogant student of medicine, he lived up to his name, Bombastus, but later changed it to Paracelsus (i.e. greater than Celsius), convinced that he was more brilliant than the Roman Physician Celsius (53 B.C. -7 A.D.). He was born in the village of Einsiedeln near Zurich, Switzerland on 14 November, 1493. In 1502, following the death of his mother, the family moved to Villach in Carinthia, Southern Austria, where he further became municipal physician and also taught chemistry. Paracelsus received his baccalaureate in medicine in 1510 and addoclorate in 1516 from the University of Ferrara. He travelled throughout Europe, British Isles, Egypt and the holy land to broaden his knowledge (Borzelleca, 1999). He returned to Villach in 1524 and remained there until 1527. Because of his fame, his lectures were well attended and he burnt medical textbooks of Avicenna and Galen. He challenged them which led to his leaving the university. Paracelsus taught at the University of Basel, Switzerland in the $1520 \mathrm{~s}$ and discovered the dose-response relationship of a poison. This insight came too late to save thousands of alleged witches executed in part of Europe for possession of poisons but it allowed
Paracelsus to introduce many potentially toxic minerals into medicine in very small doses. He used arsenic, sulphur, lead, antimony and particularly mercury, not just for syphilis but also for many other diseases. In time, physicians came to view mercury as a panacea and Paracelsus era marked the beginning of toxicology (Castleman, 2002). That notwithstanding, about 40,000 people died of ergotism in 1992 in France and Spain. Some people of India, Africa and Asia living in jungles have good knowledge of poisonous plants and animals and so they use them to catch fish, poisoning arrow heads for hunting as warfare and assassination of their foes (Garg, 2004). Even in the Europe, captives of war have poisoned their masters using poisonous plants (Castleman, 2002). By 1500 B.C., written recordings indicated that hemlock, opium, arrow poisons and certain metals were used to poison enemies or for states executions. Notable poisoned victims include Socrates, Cleopatra and Claudius (Radenkova-Saeva, 2008).

With roots extending to antiquity, toxicology is a profession which recognises that the past is often a prologue to the present (Stirling, 2006). Watson et al. (2000) provide a concise and informative review of toxicology from its Greek roots to the ubiquitous use of risk assessment. It has grown to be a science with change, evolution and even controversy based on toxicological method, concept or theory dividing the science of toxicology to analytical toxicology, aquatic toxicology, archaeological toxicocology, biochemical toxicology, clinical toxicology, environmental toxicology, experimental toxicology, forensic toxicology, genetic toxicology, immunotoxicology, industrial toxicology, inhalation toxicology, medical toxicology, neurotoxicology, ocular toxico- 
logy, ophthalmic toxicology, pathological toxicology, pesticide toxicology, phototoxicology, radiation toxicology and veterinary toxicology. The knowledge is based on Haber's law hormesis and Pare's law (Stirling, 2006). Those who developed specific techniques, theories or cannons of the field were Albert Roy, Barnes John, Bernard Claude, Bucheri Wolfgang, Casarett Louis, Christian Mildred, Clarkson Thomas, Cook Warren, Doull John, Dover Thomas, Ealon David, Feldman Robert, Fintana Abbe, Furst Arthur, Golberg Leon, Guengerich F. Peter, Haber Fritz, Hamilton Alice, Hodge Harold Carpenter, Hunt Virlma, Kaye Sidney, Kenneway Ernest, Klaassen Curtis, Legge Thomas, Lehman Arnold, Lewin Louis, Mably Thomas, Maimonides Moses, Nelson Norton, Saunders Paul, Sterner James, Taylor Alfred, Trasko Victoria, Warkany Josef, Watanabe Philip, Watin Jean, Widmark Erik, Wiley Harvey, Wilson James G., Zbinden Gerhard and Orfila Mateo, a Spanish physician who established toxicology as a distinct scientific discipline (De Sosa, 1992). Mathieu Orfila (1787-1853), a Spanish physician determined the relationship between poisons and their biological properties and demonstrated specific organ damage caused by toxins. Orfila is referred to as the father of modern toxicology. The use of animals in toxicity studies began in 1920, when J. W. Trevan introduced the use of median lethal dose $\left(\mathrm{LD}_{50}\right)$. Thereafter John Draize, an FDA scientist developed a method for testing eye and skin irritation using rabbits. Later, US National Cancer Institute (NCI) developed a test to identify carcinogenic chemicals through the daily dosing of rats and mice for 2 years. William MacBride discovered that thalidomide was the cause of phocomelia in about 1,000 babies. After this, empha- sis was laid by regulatory agencies on determining toxicity profiles of all pharmaceutical substances available for animal and human patients. In the late 1980 s, the OECD and ICH brought out the guidelines for toxicity testing of pharmaceutical substances (Parasuraman, 2011). The Ebers papyrus (corca 1500 B.C.) contains many poisons including aconite, opium, lead, copper and antimony. Sumerian texts (1400 B.C.) had referred to Gula (a female deity) who was associated with charms and poisons. Hippocrates also wrote on poison in 400 B.C., as Homer (850 B.C.) wrote on the use of arrow poison and venom in the epic tale of The Odyssey and lliad. Cleopatra (60-30 B.C.), queen of Egypt, experimented with strychnine and other poisons on prisoners and poor people. She committed suicide with Egyptian cobra (asp) sometimes used in executions. Socrates (470-399 B.C.) was poisoned with coniine and Agrippina killed Claudius to make Nero the emperor of Rome, who also poisoned Britannicus, Claudius' son using arsenic, under the directive of Locusta, a professional poisoner attached to the family. Herculaneum was destroyed by mountain Vesuvius eruption in 79 L.E. and Pliny was suffocated by volcani gases. An Italian lady, Toffana prepared arsenic-containing cosmetic. Moses Maimonides (1135-1204), a famous Jewish philosopher, born in Spain and was educated at the University of Fes wrote Treatise on poisons and their antidotes. In the quest for political stability in the Republic of Venice, the Council of ten (1310-1797) used poison to kill controversial figures. The Borgias, Alexander VI, his son Cesare and Lucrezia were well known Italian assassins during the $15^{\text {th }}$ and $16^{\text {th }}$ century. The Borgias used arsenic to poison for political and monetary gain. Pope Clement VII (1478-1534) died after 
eating Amanita phalloides. Catherine Medici, a queen of France used poisoning as a political tool during her reign. Hieronyma Spara (1659) formed Spara's secret organisation in Rome and helped women plot to kill their wealthy husbands to become wealthy widows. Catherine Monvoisin (1640-1680) was accused sorcerer and convicted poisoner in France and unfortunately she was burnt at the stake February 22,1860 . Guilia Tophania (16351719) was a supplier of poison to wives who wanted to be widows, she was later identified and executed by strangulation. In respect of that, King Louis XIV passed a decree forbidding the sale of poisons from apothecaries to unknown persons. Mattieu Joseph Bonaventure Orfila (1787-1853), a Spanish physician to Louis XVII of France who occupied a chair at the University of Paris was the first to attempt a systemic correlation between the chemical and biological effects of the known poisons which is applied on forensic toxicology. Bernadino Ramazzini (1700) is credited with knowledge of silicosis and plumbism. Percival Potts (1700) associated cancer of scrotum to Chimney sweeps (Radenkova-Saeva, 2008).

\section{TOXICITY STUDIES}

There are many different types of toxicity studies carried out for evaluation of toxic effects of therapeutic agents or potential toxicants that could pose threat to the lives of humans and animals. The traditional methods of determining toxic effects of chemicals and drugs include acute toxicity study which is carried out to determine the short time toxicity effect of a toxicant (1 s to 2 weeks), whereas subacute toxicity study is carried out to know the relative long term effect of a toxicant (4 weeks -6 months). Chronic toxicity studies are carried out to know the long term effect of a toxicant (1-1 $1 \frac{1}{2}$ years). Subacute is sometimes called subchronic, sub means under i.e. considered under acute or below chronic (Saganuwan, 2012). Other forms of toxicity studies are explained below.

\section{Single dose toxicity study}

Classical hazard and risk assessment is largely based on adverse health effects findings in experimental animals according to globally agreed test guidelines (Piersma, 2014). Zhang et al. (2015) determined maximum tolerated dose and toxicity effects of Inauhzin a novel nongenotoxic p53-activating compound in mice. The toxicity effects exhibited by the animals were acute pain, anorexia, immobility and coma. The affected animals were euthanised. Animals sacrificed at an unscheduled interval were anesthetised and necropsied (Zhang et al., 2015).

Small animals such as rats, mice, guinea pigs and rabbits are most suitable for determining the mechanism of drug absorption and bioavailability values from powder or solution formulation, whereas larger animals (dogs, pigs and monkeys) are used to assess absorption from formulations. Therefore, the understanding of physiological, anatomical and biochemical differences between gastrointestinal tracts of different animal species can lead to the selection of the correct animal models to mimic the bioavailability of compounds in the human species. However, current data indicate that no single animal can mimic gastrointestinal characteristics of humans, so human studies can never be substituted by animals. For a given purpose, selection of the right animal model is possible. For example, dogs and humans have similar stomach morphology and emptying characteristics. Pig and human colon mor- 
phology appears similar. The microbial content of the rabbit intestinal microflora is similar to that of humans. In reality, our understanding of the species differences in gastrointestinal anatomy, physiology and biochemistry is incomplete. From in vivo drug absorption studies, it is difficult to assign the observed differences in bioavailability to any factor. Overall, we need more mechanistic studies to delineate the effects of anatomical, physiological and biochemical differences between species on overall drug absorption (Kararli, 1995). The canine neck may be used as a modelling tool for biomechanical investigations of the human cervical region (Shairr et al., 2006).

There are currently several factors driving a move away from the reliance on in vivo toxicity testing for the purposes of chemical safety assessment. Progress has started in the development and validation of non-animal methods. However, recent advances in the biosciences provide exciting opportunities to accelerate this process and to ensure that the alternative paradigms of hazard identification and risk assessment deliver lasting 3Rs benefits, whilst improving the quality and relevance of safety assessment. The NC3Rs, a UKbased scientific organisation that supports the development and application of novel 3Rs techniques and approaches held a workshop recently, which brought together over 20 international experts in the field of clinical safety assessment (Burden et al., 2015).

\section{Fixed dose procedure}

Fixed dose procedure (FDP) is used to assess the non-lethal toxicity rather than lethal dose. The investigational product is administered at fixed dose levels of 5, 50, 500 and $2000 \mathrm{mg} / \mathrm{kg}$ and the animals are observed for a short time period (Stallard
\& Whitehead, 1995). Animals of same species are used at each level using four pre-identified starting doses which can be selected based on the globally harmonized classification system (Saganuwan, 2012).

\section{Up-and-down procedure}

Up-and-down procedure (UDP) was developed by OECD in 1981 and revised many times. For an agent suspected to be relatively safe, either $2000 \mathrm{mg} / \mathrm{kg}$ or 5000 $\mathrm{mg} / \mathrm{kg}$ can be administered orally to the first experimental animal and observed for $48 \mathrm{~h}$. if the animal dies, a second and third animal can be dosed concurrently and observed for $48 \mathrm{~h}$. If these two die and the test dose is $2000 \mathrm{mg} / \mathrm{kg}$, the $\mathrm{LD}_{50}$ may be assumed to be below $2000 \mathrm{mg} / \mathrm{kg}$ (OECD, 1987; 2000a,b; 2001a,b,c). Although 515 animals can be used, Saganuwan et al. (2011) has reduced the number of animals to 6 using 3 reversals. However, 2 animals can be used with one reversal, i.e. 1 dead and 1 survivor (Saganuwan, 2014). The prepared solution of a toxicant should be uniform and given by gavage. In rodents, the volume should not exceed $1 \mathrm{~mL} / 100 \mathrm{~g}$ body weight (NIEHS, 2000).

\section{Toxicity study of snake venom}

The calculation of median lethal dose $\left(\mathrm{LD}_{50}\right)$ and effective dose fifty $\left(\mathrm{ED}_{50}\right)$ have been developed and modified. $\mathrm{LD}_{50}$ value of snake venom can be calculated using 1-4 animals, whereas Spearman Karber's method (Carter, 1980) and ideal median lethal dose formula developed by Saganuwan (2011) can be used for estimation of $\mathrm{ED}_{50}$ for snake antivenom. Since $\mathrm{ED}_{50}$ is equal to $2 \mathrm{LD}_{50}$ or $3 \mathrm{LD}_{50}$, the $\mathrm{LD}_{50}$ of snake venom can be calculated from the $\mathrm{ED}_{50}$ formula most especially for $\mathrm{Mi}$ crarus fulvius venom and anti-venom using mice of about $20 \mathrm{~g}$ and safety margin of 10,000 (Saganuwan, 2016). 


\section{Repeated dose acute toxicity testing}

Repeated dose acute toxicity testing (RDATT) lasts for a minimum of 28 days (1 month). The test agent is administered daily using uniform concentration at determined dose orally or parenterally. Rodents 5-7 weeks of age are preferred with average weight of $20 \%$ the standard deviation. Animals are observed for toxicity signs (Saganuwan, 2012). Since gestation period of rodents especially mice and rats is about 3 weeks, mutagenicity testing can be done to assess the effect of drug on gene especially deoxyribonucleic acid (DNA). Expected toxicity signs include but are not limited to chromosomal aberration, DNA duplication, insertion, inversion and translocation that may lead to carcinogenesis. In vivo mutagenicity which is dose dependent is used to determine the case-by-case basis risk assessment of the test substance. Mutagenicity studies with transgenic animals are more appropriate assay techniques to determine the toxicity of a test substance (Eastmond et al., 2009; Gholami et al., 2010).

\section{Repeated dose toxicity study}

Repeated dose toxicity (RDT) is one of the key regulatory endpoints in the hazard assessment of chemical substances (Yamada et al., 2014). In most cases, the safety evaluation of new anti-cancer small molecule pharmaceuticals includes repeated dose toxicity studies in both rodents and non-rodents. But retrotoxicology data illustrate that non-rodent studies make an important contribution to human risk assessment (Deavall et al., 2014). Entry into the critical pre-clinical "Good Laboratory Practice" stage of toxicology testing triggers significant R\&D investment yet $>20 \%$ Astra Zeneca's potential new medicines were stopped for safety reasons in this GLP phase alone. By smart loading 2 week repeated dose toxicity studies and a comprehensive assessment of cardiovascular safety, a potential $50 \%$ reduction in attrition in the GLP phase can be achieved. This will reduce animal use overall, save significant R\&D costs and improve drug pipeline quality (Kavanagh et al., 2014). Micro sampling techniques and enhanced analytical sensitivity provide scope for reducing numbers of satellite animals on rodent toxicology studies. It is possible to obtain individual serial toxicokinetic profiles from reduced numbers of satellites attached to each group (Lawrence et al., 2014). Metabolome analysis of two different mixtures and their respective enantiomers indicated no biological relevant differences regarding the qualitative toxicity towards the assumed target organs as well as quantitative amount of toxicity, thereby confirming the toxicity equivalence of the enantiomers (Parra et al., 2014). An analysis of target organ toxicities in man toxicity studies for 77 Astra Zeneca candidate drugs was conducted across a range of therapy areas. In the rodents, the most frequently affected organ was the liver, followed by adrenal glands, kidney, spleen, bone marrow, and thymus. In nonrodents, liver and thymus were the most frequently affected organs, followed closely by the testes and gastrointestinal tract. Therefore, the use of non-rodents as a second species in toxicity testing to support human safety is important (Lees et al., 2014). Aged rats are more prone to ecstasy neurotoxicity than adolescent rats suggesting that age is an important determinant for the neurotoxic events promoted by ecstasy (Azevedo et al., 2014).

Specific organ acute toxicity study

Specific organ acute toxicity study (SOATS) is very necessary for drugs de- 
veloped for treatment of specific organ diseases as seen in respiratory diseases in which rats are used. The animal is exposed to aerosol-like preparation for $4 \mathrm{~h}$ and monitored for 14 days (OECD, 2000a,b). For ophthalmic agent use, 0.5 $\mathrm{mL}$ of a test substance ( $1 \%$ solution) is administered to an animal eye and observed as for respiratory and for skin $0.5 \mathrm{~g}$ of a test substance is applied to surface of animal's skin (Curren \& Harbell, 1998; York \& Steilling, 1998). Skin sensitisation test can be carried out using guinea pig as a model. The tests used are Draize test, open epicutaneous test, optimisation test, split adjuncut test, guinea pig maximisation test, Buelier test and murine local lymph node assay (WHO, 2008). Neurotoxicological study is carried out in adult rodents. The test substance is administered for 30-90 days. An in vitro model is preferred for safety value (OECD, 2010).

\section{Reproductive toxicity study}

With respect to reproductive toxicity, it is clear that vaccination during pregnancy might be important to protect the mother as well as the child, but an adjuvant might be a risk especially very early in pregnancy (Van Der Laan et al., 2014a). The P53+/- mouse model may be the preferred model for compounds with direct or equivocal evidence of genotoxicity, while the $\mathrm{rasH}_{2}$ mouse model developed by the Central Institute for Experimental Animals in Japan, is the only model acceptable for compounds with positive, equivocal or negative genotoxicity findings. The $\mathrm{rasH}_{2}$ model is becoming the choice of pharmaceutical companies that have adopted an alternative mouse model into their carcinogenicity risk assessment paradigm. The proposed modification of the ICHSI guideline addresses the elimination or replacement of a 2 -year rat study based on a weight-of-evidence argument to improve human risk assessment while reducing, refining and replacing (3R) animal testing. In case-by-case situations, the alternative mouse models have the potential to contribute to this weight-ofevidence, and may be the only carcinogenicity study needed to adequately assess carcinogenic risk (Bower, 2014). The impact of testing in a second species for embryofoetal developmental toxicity was discussed during a 2010 ICH workshop in Tallinn, Estonia. It was proposed to review the frequency with which the results from studies in the rat versus rabbit have driven the lowest observed adverse effects level (LOAEL) and exposure margins in risk assessment for pharmaceuticals (Van Der Laan et al., 2014b). Nonhuman primates (NHP) models play an important role in the development and safety assessment of biopharmaceuticals depending on the particular properties of the drug candidate. In many instances, the experimental use of NHPs is subject to special regulations and animal welfare considerations among which the $3 \mathrm{R}$ efforts should focus on reduction and refinement. For reduction, some guideline changes related to biologics - ICH M3 (R2) and ICH S6 $\left(\mathrm{R}_{1}\right)$ - can provide an option for using lesser number of NHPs. ICH S6 $\left(\mathrm{R}_{1}\right)$ makes specific recommendations on how many live infants are required per group for a NHP pre-and postnatal development study. This recommendation in conjunction with the use of reference data and normogram data can be used to reduce the number of NHPs needed for developmental toxicity testing. Also, under certain circumstances, the conduct of dedicated reproductive toxicity evaluation as per ICH S5 $\left(\mathrm{R}_{2}\right)$ can be incorporated in chronic toxicity studies thus further lowering the demand for NHPs. Therefore, re- 
finement should be a key, focus of any $3 R$ efforts in order to optimise the use of NHP models. Recent work has provided statistical power estimates for some fertility parameters relative to group size that will be used in developing appropriate study designs. Also, the potential of combining pre-and postnatal testing with juvenile toxicity testing has been raised. Various options are available to optimise NHP DART testing in the spirit of $3 R$ (Weinbauer, 2014). In the case of drugs developed for children, juvenile animals are used as models of human children. Dermal drugs are normally developed using the minipig as a testing species due to similarities between human and minipig skin. For minipigs, dosing of young animals from weaning at 4 weeks of age is straight forward. However, for younger preweaned animals, there is a high risk of interference with dosing site by the mother or siblings. This potentially prevents studies that would evaluate effects of drugs in animals of equivalent human age 0 to 2 years. However, dermal studies on minipigs younger than 4 weeks of age can be performed (Makin et al., 2014).

\section{One-generation reproduction toxicity testing}

This type of test is conducted in some generation of animals comprising male and female animals. The agent is administered for a duration of one complete spermatogenic cycle in male animals and for two complete estrus cycles for females. Rodents are preferred. After the completion of administration, the animals are allowed to mate. The test compound is administered to the females during the period of pregnancy and nursing. The sperms are collected for analysis. Number of offspring and their sexes are recorded. The number of live and dead pups are also recorded and live pups are weighed daily until they are weaned. Very few pups can be sacrificed for histopathology (OECD, 2015a).

\section{Two generation reproduction toxicity studies}

They are similar to one-generation reproduction toxicity testing. After the administration, the animals are mated after which female animals are separated. Sperms are collected for analysis. Thereafter, the test substance is continuously administered to pregnant females which are observed regularly for toxicity signs including mortality. After parturition, nursing rats are administered the test drug and the mortality of the pups ( $1^{\text {st }}$ filial generation) is observed. From the $F_{1}$ generation, one male and one female animal are selected. $\mathrm{F}_{1}$ offspring are not allowed to mate until they have attained full sexual maturity, and pairs without a pregnancy are evaluated for infertility (Oliveira et al., 2010). Necropsies and histopathological examinations are carried out. At the end of the study, the animals are sacrificed for gross pathological and histopathological examinations (OECD, 2015b; Matsuura et al., 2005; Ganiger et al., 2009). During the reproduction toxicity studies, developmental and embryo toxicity can be carried out together or independently. Rodents are preferred. The compound is administered between $8^{\text {th }}$ and $14^{\text {th }}$ day of pregnancy and embryolethal effects are studied. On the $21^{\text {st }}$ day of the study a caesarean section is performed and felaser with haemorrhagic bullae, limb malformations, exencephally, cleft palates, open eyelids, detail deformities, mortality and the number of live and dead animals are noted. Embryo toxicity assays such as embryonic stems cell test, micromass embryotoxicity assay and whole rat embryotoxicity assays can be 
done (Kimm-Brinson \& Ramsdell, 2001; Hofmann et al., 2002; Booth et al., 2010). During generation reproduction toxicity study, genetic toxicity testing can be carried out to identify gene mutations, chromosomal changes and alterations on the DNA sequency. This test is conducted in all species of animals. But in the whole animal model, rodent species is preferred. Genetic toxicity is assessed using the rodent chromosomal assay, dominant lethal assay, mouse-specific locus test, micronucleus test, heritable translocation assay and sister chromatid exchange assay (Oliveira et al., 2014).

\section{Subchronic toxicity testing}

The test is conducted for a period of 90 days (3 months). In this type of study, subchronicity factor gives an indication of the cumulative effects of poisons. It is the ratio of acute $\mathrm{LD}_{50}$ to 90 days $\mathrm{LD}_{50}$. A compound though may have low acute toxicity, but it has the tendency to accumulate in the body tissues and can cause subacute or chronic toxicity. Such toxicants are termed as cumulative poisons, e.g. DDT, lead, fluorides etc. (Saganuwan, 2012). A satellite group may be included in the study protocol, and this group has both a control group and a high dose group (Muralidhara et al., 2010). Tissues are collected for gross pathology and histopathology.

\section{Chronic toxicity testing}

It is a long term toxicity study that last as long as the life-span of the test animals usually 1-2 years. Rodents such as mice and rats are usually used. Chronicity factor gives an indication of the cumulative effects of poisons. It is the ratio of acute $\mathrm{LD}_{50}$ to $1-2$ years $\mathrm{LD}_{50}$. This type of test can be conducted on drugs developed for terminal diseases such as cancers, AIDs etc. (Saganuwan, 2012). A satellite group may be included in the study protocol. This group has both a control group and a high-dose group. The animals are observed for normal and abnormal body functions and biochemical parameters should be measured. Tissue are collected for gross and histopathology (Jaijoy et al., 2010). Carcinogenicity testing is under chronic toxicity testing in which both rodent and non-rodent species of animals are used. The test can be terminated after $1 \frac{1}{2}$ years in case of mice and hamsters and after 2 years in case of rats. Haematological analysis is performed in healthy animals after 1 and $1 \frac{1 / 2}{2}$ years in mice and rats respectively and the study is terminated. The animals are sacrificed for gross pathology and histopathology (Saganuwan, 2012).

\section{ADVANTAGES OF TOXICITY STUDIES}

Apart from accidental discoveries of toxicants, malicious killings with some toxic agents have also helped recognition of the importance of toxicology. Kothari et al. (2015) prepared and tested a conjugate vaccine using pneumococcal surface protein A (PSPA) from Streptococcus pneumonia as the carrier protein and Piao et al. (2014) generated and tested three proteins comprising PSPA families 1 and 2 in mice using the method of Saganuwan (2011). Ahmed (2008) isolated and characterised Bdellovibrionacceae - unique, predatory, endoparasitic Gram-negative bacteria. They prey in other Gram-negative bacteria giving them potential as biological control agents and so its $\mathrm{LD}_{50}$ was determined in the host using the method of Saganuwan (2011). In this regard quick chick embryo chorioallantoic membrane (CAM) assay was used as an alternative predictive 
model in acute toxicological studies for cyclophosphamide, cisplatin, vincristine, carmustine, campothecin, aloin, mitomycin $\mathrm{C}$, actinomycin $\mathrm{D}$, melphalan and paclitaxel (Kue et al., 2015) using the method of Saganuwan (2011). Any drug has the potential to cause an adverse reaction which is unwanted, unpleasant, noxious or harmful consequence usually associated with the use of a medication that has been administered at a standard dose by the proper route, for the purpose of prophylaxis, diagnosis or treatment (Wen et al., 2014). Cao et al. (2014) identified a Bacteriovorax sp. isolate as a potential bacterium against snake head fish pathogen Aeromonas veronii using the method of Saganuwan (2011). Aeromonas veronii affects the quality of fish leading to severe losses to marketing (Cao et al., 2014). However, a glycoprotein-based nativesubunit vaccine for fish against Aeromonas hydrophila known to be causative agent of bacterial haemorrhagic septicaemia or red pest in freshwater fish was developed and validated (Ciftci et al., 2016). Hepatitis A virus and its indicator were concentrated and detected from artificial seawater using zeolite (Cormier \& Janes, 2016) using the method of Saganuwan (2011). Death is the ultimate adverse drug event (Litt, 2015). Ibiam et al. (2014) determined median lethal concentration $\left(\mathrm{LC}_{50}=3.259-6.06 \mathrm{mg} / \mathrm{L}\right)$ of Psychotria microphylla in Clarias gariepinus. Saganuwan \& Onyeyili (2016) extrapolated $\mathrm{LD}_{50}$ of mice to rat, hamster, guinea-pig, rabbit, monkey, cat, dog, baboon, children and adult humans using human equivalent dose formula in recognition with principles of reducing, refining and replacing (3R). The preferred rodent species for toxicity studies is the rat, although other rodent species may be used. The test is conducted using a single sex in order to reduce variability and as a means of minimising the number of animals used (OECD, 2000a, b). In a situation where sensitivity is noticed between the sexes, females could be more sensitive and can be used (ASTM, 1987). However, experience has shown that male mice are more sensitive to hydrocortisone and piroxicam in comparison with female mice. Therefore, knowledge that metabolic activation is required for a chemical's toxicity can also indicate that males may be a more sensitive sex (NIEHS, 2000). Since determination of acute oral toxicity is usually an initial screening step in the assessment and evaluation of the toxic characteristics of all compounds, the methods so far utilised for the determination of $\mathrm{LD}_{50}$ went through entire process of validation with different categories of substances before its final acceptance by regulatory bodies (Akhila et al., 2007). The rule of thumb is that all animals should be handled according to the international guiding principles for biomedical research involving animals (CIOMS, 1985). Ameni et al. (2014) reported that the $\mathrm{LD}_{50}$ of Casearia sylvestris Sw (Salicaceae) was greater than $2100 \mathrm{mg} / \mathrm{kg}$. Saganuwan et al. (2008) estimated $\mathrm{LD}_{50}$ of potassium permanganate at dose level of $1499.7 \mathrm{mg} / \mathrm{kg}$ body weight and the article has been indexed by PubMed. Saganuwan et al. (2011) determined $\mathrm{LD}_{50}$ of aqueous extract of Abrus precatorius leaf at dose level of $2823.7 \mathrm{mg} / \mathrm{kg}$ body weight in mice. The article was published by Herba Polonica based in Europe. The seed of Abrus has antidiabetic effect but should be boiled to reduce strength of the toxic principle abrin present in the plant (Saganuwan, 2009). After Paracelsus (1493-1541) recognised that all substances are poisons, the right dose differentiates a poison from a remedy and puts 
forth the concept of dose-dependency of the toxic-effects of substances. This principle holds true even today (Garg, 2004). During the drug discovery and development research, to prioritise a compound with less toxicity is important especially in the early drug discovery stage. Since only a limited amount of samples can be available at this stage, mammalian in vivo test systems are not adequate for that purpose. A variety of cell-based assay systems for toxicity screening has been established, but these assays do not necessarily reflect the actual phenotype of mammalian toxicity, which makes it difficult to predict the precise safety profile of compounds (Yamashita, 2015). Generation of animal data using ever greater dose groups and numbers of animals is probably not the appropriate solution not only on ethical or cost reasons, but also in relation to addressing the issue. The solution is more likely to be found by exploring the mechanistic basis of how such substances act at the molecular and cellular level and these interactions may lead to toxicity at the organism level according to dose, duration and life stage of exposure (Munn, 2014). The principles of the $3 \mathrm{R}, \mathrm{Re}$ placement, Reduction and Refinement, are being increasingly incorporated into legislations, guidelines and practice of animal experiments in order to safe-guard animal welfare. Data from 36 reductions projects were collected retrospectively from work between 2006 and 2010. Substantial reduction in animal use was achieved by different strategies, including improved study design, method development and project coordination. Major animal savings were shown in both regulatory and investigative safety studies. If a similar (i.e. 53\%) reduction had been achieved simultaneously within the 12 largest pharmaceutical companies, the equivalua- tion world-wide would be about 150,000 rats annually (Oberg et al., 2014a, b). Suggesting that median lethal doses are still used, compounds that have negligible tendency to accumulate and are rapidly metabolised have the same chronic $\mathrm{LD}_{50}$ values as the acute $\mathrm{LD}_{50}$ values (Hamburger, 1989). However, with toxicants to which the subjects develop tolerance, the dose required to produce lethality on repeated exposure increases. For such agents, a chronicity factor is determined. Chronicity factor gives an indication of the cumulative effects of poisons. It is the ratio of acute $L_{50}$ to chronic $L_{50}$ values (Saganuwan, 2012). Dogs have historically been useful, informative models in the development and discovery of many novel cancer strategies (Gordon et al., 2009). The pharmacological manipulation of $\mathrm{CB}_{2}$ receptor in Sprague-Dawley rats may represent a potential therapeutic tool for the treatment of migraine (Greco et al., 2014), suggesting that animal models of migraine reflect distinct facets of this clinically heterogeneous disorder and contribute to a better understanding of its pathophysiology and pharmacology (Gikermann-Haerter \& Moskowitz, 2008).

Acute poisoning and snake bite kill up to half a million people in the world each year (Buckley, 2014). Snakes and other venomous animals bite humans and other animals for protection or food. Of the 2800 species of snakes, only about 200 species have caused death or permanent disability by biting humans. In Asia, the highest incidence of snake bite to death was 162 per 100,000 , in Africa 497 per 100,000, Australia 4 per 1000-2000, in Europe 14 per 200 in the last hundred years, in Latin America (Brazil) 25\% of death per 19,200 each year and in the USA $12-15$ deaths per 7,000 bites (Sawai et al., 1976; Warrell \& Amett, 1976; Lal- 
loo et al., 1995; Warrell, 2004; 2005; Cook \& Zumila, 2009). One million people throughout the world are bitten each year by poisonous snakes. Of this number some 100,000 die and another 300,000 will suffer some form of disabilities for the remainder of their lives. In view of this Odessa (2014) invented and patented alkaline sodium silicate composition to inhibit the toxic effects of venom and treat venomous bites and stings based on the method of Saganuwan (2011) whereas the effective dose 50 of the antivenom was determined by Sanchez et al. (2003). Asiedu-Gyekye (2014) determined $\mathrm{LD}_{50}$ of polyhexamethylene guanidine and polyexamethylene guanide used in the treatment of raw water at dose levels of 600 and 16 $\mathrm{mg} / \mathrm{kg}$ body weight respectively. Exposure to a wide range of toxic products with spectrum being broadened due to introduction of a diverse range of pesticides, household cleaners and drugs from time to time could cause implementation of precaution programmes of prevention and identification of high risk circumstances, which can help in reducing morbidity and mortality (Peshin et al., 2014).

\section{DISADVANTAGES OF TOXICITY STUDIES}

The indiscriminate use of pollutants, such as heavy metals, surfactants and drugs, generated by anthropogenic activities is causing a tremendous hazard to both aquatic and terrestrial habitats and to human health. Therefore, in recent years the interest towards the toxic effects of these molecules on living organisms has increased (Forni, 2014). Cobalt intoxication has become more frequent due to the wide use of metal cobalt hip implants. Only a few patients have systemic symptoms of poisoning. Cobalt toxicosis may be asso- ciated with hypothyroidism, polyneuropathy, impairment of cranial nerves and cardiomyopathy (Deschamps, 2014). Lowlevel metal and insecticide exposure contributes much more towards causation of chronic disease and the impaired functioning than previously thought. It will go a long way in developing new approaches for determining the safety of pesticides and the need for innovative regulatory policy to protect human and environmental health (Hundal, 2014). Octadecanoic acid was reported to induce lung damage in fish (Ibiam et al., 2014). Ufot et al. (2014) reported that crude oil caused decreased litter size, follicular stimulating, lutenizing hormone and progesterone in rats which may decrease rat population. They concluded that reproductive toxicity is associated with oral exposure to crude oil. Tityus serrulatus venom induces a severe systemic inflammatory condition caused by the production of eicosanoids (Faccioli, 2014). Inhalation of airborne nanoparticles has been reported during manual activities using typical fume hoods and manufacturing processes. The current occupational exposure limits to nanoparticles were under development and there are dose metric needs to be harmonised for exposure assessment and toxicological studies. The challenge of current efforts is to further investigate occupational exposure and the associated biological responses (Tsai, 2014). Camberos (2014) fed mice with Jatropha curcas fermented with Rhizomucor $\mathrm{sp}$. for a period of 2 weeks. The other group of mice was fed unfermented $J$. curcas. Unfermented $J$. curcas killed all the mice in that group. He concluded that Jatropha seed cakes treated by fermentation were adequately detoxified and hence, can be fed to cattle. Jatropha contains antinutritional products such as tryp- 
sin inhibitors, lectins, phytates and pherbol esters that limit its use as a complementary food for livestock (Camberos, 2014). Before use, plants that have toxic or anti-nutritional elements such as oxalates, tannins, phytates, nitrates/nitrites and others should be subjected to soaking and or boiling in water, toasting or fermentation to remove the toxic elements (Mahajan \& Dua, 1994). Therefore, plants should not be abused, as the lack of controlled experiments means toxic levels have not been defined and the plant constituents may affect more than one body system. Use of more than therapeutic values may lead to overdoses with serious consequences (Saganuwan, 2009). Styrax camporum extract showed genotoxicity to Chinese hamster lung fibroblasts (V79 cells) at $60 \mu \mathrm{g} / \mathrm{mL}$. The genotoxic effect was attributed to the presence of benzofuran lignans, egonol I and homoegonol (Tavares et al., 2014) which were also responsible for antitumour activity at 9.1 $\mu \mathrm{g} / \mathrm{mL}$ against the Hela cancer cell lines (Oliveira et al., 2014). Lee et al. (2014) conducted 90-day repeated dose toxicity and genotoxicity of Evodia officinalis and concluded that the plant did not show mutagenic potential, chromosomal aberration and micronucleus formation. Every year, more than hundred new drugs are approved in Japan. All of them have some scientific uncertainty in terms of efficacy and safety at the time of drug approval. A better understanding of regulatory science in the field will contribute to increasing efficiency of drug development and providing a better drug to patients (Uyama, 2015). The challenge for toxicologists in future will be for them to take an even more active role in opposing more effectively poor science, including inadequate interpretation of data such as those about supposed risk that are not based on an objective evaluation of the available data, and regulatory decisions that defy common sense (Vale, 2014). Dose-response curves are often drawn and considered in the context of the "dose makes the poison". This is described simplistically as increasing dose levels result in increasing adverse effects. This can be result of a monotonic increase or decrease in a response that is associated with an adverse effect. However, non-monotonic dose responses (NMDRs) are biological effects with dose-response curves deviating from the usual shape of a continuous response reaching saturation at high doses and showing no measurable response at low doses. Some of these effects may be adverse on highly sensitive signalling pathways triggered by steroid hormones or thyroid hormones (Tsatsakis et al., 2014).

\section{POSSIBLE SOURCES OF UNCERTAINTY}

Toxicogenomics is a mature field, which provides invaluable information on the molecular events preceding or accompanying toxicity. Most traditional uses of transcriptional profiling and other-omics data in toxicology are: mode-of-action analysis, classification/prediction, and biomarker discovery. While these applications are very informative for the regulatory decisions, they do not contribute to quantitative evaluation of the margin of safety and/or characterisation of the uncertainties in species-to-species extrapolation and population variability. Studies that explore the shape of dose-response relationships at the molecular pathway level, and the impact that inter-individual differences in given expressions patterns may have on both efficacy and safety outcomes, represent some of the novel frontiers in toxicogenomics. Dose-response 
toxicogenomic data may be used for calculating the point-of-departure at which either adverse or adaptive "molecular pathology" phenotypes are observed after exposure to chemicals. Aggregation of the dose-response genes into pathways further improves the linkages between mechanistic understanding and estimating the margin of safety. In addition, the challenge of elucidating the genetic determinants of inter-individual's differences in toxicity may be met through a combined analysis of the toxicity phenotypes, genetic polymorphisms, and gene expression data from the population-base experimental in vivo and in vitro model systems. The intricate interplay between genetic polymorphisms and gene expression requires careful consideration of the genetic background dependent and independent toxicity pathways. Therefore, as the number of toxicogenomic studies which incorporate dose-response and/or population-based study designs is in the rise, the applicability of such data to next-generation health risk assessments will also increase (Ruzyn, 2014). For example, there is uncertainty concerning the safety implications of toxic xenobiotics as they are also associated with a variety of diseases such as inborn errors of metabolism. Phospholipidosis is also a common finding in nonclinical toxicology studies designed to enable clinical trials and marketing applications for new drugs. It is usually associated with cationic amphiphibic drugs (CADs) with distinct structures; they contain both hydrophobic and hydrophilic domains, which enables transit through cellular membranes and intracellular concentrations. This chemical property may be desirable for drugs that act on intracellular targets and could be related to pharmacodynamics and drug efficacy (Hastings, 2014). For carcinogenic endpoint, it is generally assumed that no threshold dose level exists. In this case determination of dose level for regulation relies on mathematical model to relate predicted risks to dosage (Barnes \& Dourson, 1988). Originally, tolerance distribution like the logit and probit models used for non-carcinogenic responses were used (Krewski \& Brown, 1981). A model called the multistage model developed by Armitage \& Doll (1961) has become very popular for cancer risk estimation. The statistical model involves up to about seven stages and appears to fit observed cancer incidence curves reasonably well. A modified form, referred to as the linearised multistage model is described by Howe et al. (1986) and dates risk to low doses. Perhaps the most difficult problems in toxicologic risk assessment are the conversion of animal data to humans. Ideally, quantitative interspecies extrapolation should take into account known species differences. Dose equivalency between species has traditionally been based on body weight and body surface area. Travis \& White (1988) have recommended an intermediate scale based on body weight to the $3 / 4$ power for dose conversion between species. The application of transgenic animal models to elucidate human pathways of drug metabolism and chemical toxicity has been proposed (Wolf et al., 2014). The omic technologies have not been, and never will be the panacea for all the challenges in toxicology for the fact that they have yet to find their ways into regulatory acceptance (Gant, 2015). Both animal tests, as well as their various in/ex vivo, in vitro and in silico replacements are often not sufficiently predictive of their intended toxic endpoint (Bender, 2014). For example, human oligodendrogenesis is the most sensitive endpoint being 10 times more sensitive than human 
neurogenesis which has the least sensitive endpoint ( $\mathrm{IC}_{50}: \mu \mathrm{M}$ and $23 \mu \mathrm{M}$ ). Sensitivity of murine neurogenesis and oligodendrogenesis differs only slightly, $\mathrm{IC}_{50}: 10$ $\mu \mathrm{M}$ and $14 \mu \mathrm{M}$ (Dach et al., 2014). Also, cleft palate is a craniofacial birth defect that affects one in every 700 newborns worldwide. This defect results from a disruption in the development of the secondary palate (palatogenesis) which can be caused by several genetic and environmental factors. Morphologically, palatogenesis in mice, rats and human consists of palatal shelves, development, growth, elevation, content and fusion. The mouse is the mostly commonly used species for the study of palatogenesis and the rat is the species used in human risk assessment studies; although it is assumed that the molecular pathways underlying palatogenesis in mice, rats and humans are similar, similar expression patterns between mice and rats suggest that the principal pathways underlying pathogenesis are conserved in both species (Vicario et al., 2014).

\section{ANIMAL WELFARE ISSUES}

Animal welfare comprises the state of the animal body and mind, and the extent to which its nature (genetic traits manifest in breed and temperament) is satisfied (Duncan \& Fraser, 1997). The discussion about the protection of animals for scientific purposes is always important in the European Union. A recent directive (2010/63) renewed the previous one after 25 years, further emphasising that animals should only be used when clearly needed. In cosmetics legislation, animal data are no longer allowed for regulatory purposes. Stimulation of in vitro approaches is therefore important in the research activities. Reproduction toxicity, carcinogeni- city and sensitisation are actual topics with promising perspective to reduce animal use (Van Der Laan, 2014). ICH M (R2) guidance has helped clarify the timing of reproductive toxicology studies in drug development. Toxins may be evaluated qualitatively using nature of toxins, quantitatively using chemistry of toxin and their concentration. Colorimetry and spectrophotometry can be used for qualitative analysis of toxins whereas infrared spectroscopy, gas chromatography, high pressure liquid chromatography and immunoassay techniques may be used to quantify toxins (Parasuraman, 2011). However, the guidance remains general and may not apply to all drug candidates for all circumstances. Therefore, in addition to the guidance document, other factors such as pharmacological trial design should be considered when planning the timing of these studies. In embryo-foetal development studies, exposure to drug could be indicated by the presence of maternal toxicity, and $\mathrm{ICH}$ did not require collection of toxicokinetic data in these studies. This results in the absence of toxicokinetic data in some studies, and assessment of risk of pregnant mothers is done using the conversion of animal dose to human-equivalent dose based on body surface area. This approach is less precise and occasionally not accepted by regulatory agencies. In rabbit embryo-foetal development study, the absence of PK/ADME data, coupled with the occasional absence of TK data, has led many to question the relevance of the absence of this species in risk assessment. A survey has been conducted to address this question. Under the EMA regulation, planning for the juvenile animal study should be submitted early in development. Two approaches are generally considered when designing the juvenile animal study. In the 
targeted design approach, the study will evaluate large organs of concern in the target population. In the absence of target organs, the modified general toxicity screening approach may be used to identify hazards in the young and developing animals (Hew, 2014). Before conducting any toxicological testing in animals or collecting tissue/cell lines from animals, the study should be approved by the Institute of Animal Ethics (IAEC) or the protocol should satisfy the guidelines of the local governing body. The guidelines differ from region to region, country to country and institution to institution (Schedule, 1995). Low, medium and high doses selected should be sufficient to identify the target organ toxicity (Robinson \& Chapman, 2009).

\section{ALTERNATIVE METHODS OF TOXICOLOGICAL RESEARCH}

According to Assuring Safety Without Animal Testing (ASAT) principle, risk assessment may ultimately become possible without the use of animals (Fenton et al., 2014). The ASAT concept takes human disease mechanisms as starting point and tries to define if activation of these mechanisms by chemical exposure in in vitro models can be used for toxicological risk assessment. Chemical analogues identified by chemo-informatic tools are presumed to induce similar biological responses, such as similar toxicities. Therefore, toxicity may be predicted by readacross from members of the same chemical class. However, compounds with seemingly subtle changes in chemical structure, e.g. the classical example of 2$\mathrm{AAF}$ and 4-AAF, show relevant changes in toxicological properties, thus making prediction solely based on chemoinformatics insufficient. This especially holds true for more complex toxicological endpoints related to repeated dose toxicity. Using omics data provides a better prediction of repeated dose toxicity (Jennen et al., 2014). In vitro testing is carried out in two or three different bacteria and mammalian cells to cover the end points of genemutations clastogenicity and aneuploidy. The test generally includes a bacterial reverse mutation assay. The chance of an additional test depends on the chemical structure/class of the substance (Gholami et al., 2010). A major goal of human in vitro toxicogenomics is to improve the assessment of the toxic hazard and ultimately the risk due to the exposure to chemicals with assays based on human cells lines rather than in vivo in rodents. Using high-throughput gene expression read-outs, this approach requires solid and robust computational pipelines and tools in order to identify responsive genes and biological pathways capable of predicting toxicity of chemicals (Van Delft et al., 2004). Classification of untested chemicals, which make up more than $95 \%$ of all chemicals on the market, is not possible without some form of prediction based on a simplified alternative biological model or a simplified chemical structure-activity relationship. The OECD QSAR Toolbox is a freely available software that implements structure based approaches to the prediction of toxicological data: it exploits the possibility of combining chemical and biological information to assess the toxicity of a query chemical starting from the toxicity and structural data of analogue chemicals. A priority of OECD for the near future is to implement Adverse Outcome Pathways (AOPs) into the Toolbox, and provide the investigators with additional tools to predict complex toxicological endpoints (Benigni \& de Knecht, 2014). The use of engineered nanomate- 
rial has grown rapidly in a number of industrial and consumer products. At the same time, concerns of possible harmfulhealth effects of engineered nanomaterial have increased, and this development may seriously jeopardise the successful use of these valuable materials (Savolainen et al., 2013). A key element of using in vitro toxicity data in chemical risk assessments is linking the effect of concentrations from in vitro assays to those in the target tissue in vivo. This extrapolation requires an estimate of in vivo uptake and clearance. However, currently available in vitro kinetic assays have significant limitations in the in vitro system (Yoon et al., 2014). Therefore, there is need for functional association of the identified biomarker activities with each cell system that can be used to support the elucidation of adverse outcome pathways connecting molecular in initiating event to specific human adverse effects (Berg et al., 2014). The use of recreational drugs has changed in recent years due to the rapid emergence of new psychoactive substances known as "smart drugs" or "legal highs" which have the biased reputation of being safe, the vast majority, has hitherto not been tested and several fatal cases have been reported, namely for synthetic cathinones, with pathological patterns comparable to amphetamines (Araujo et al., 2014). Therefore, there is need to assess toxicity effects of cathinones in experimental animals with a view to exploring their toxicity effects. An international expert group which includes 32 organisations (pharmaceutical and biotechnology companies, contract research organisations and regulatory bodies) has shared data on the use of recovery animals in the assessment of pharmaceutical safety for early development. The group has used these data as an evidence base to make recommendations on the inclusion of recovery animals to toxicology studies to best assess human safety, while reducing animal use. The initiative is led by the NC3R in collaboration with the Medicines and Healthcare Products Regulatory Agency (MHRA). Recovery animals are used in pharmaceutical development to provide information on the potential for a toxic effect observed in animals to translate into long-term human risk. They are included in toxicology studies to assess whether effects observed during dosing persist or reverse once treatment ends. An analysis of individual study and programme design shows that there are opportunities to reduce the use of recovery animals in certain circumstances, which would not impact drug development (Sewell \& Chapman, 2014). In human risk assessment any relevant exposure route has to be addressed. Consequently, for numerous chemicals no adverse effect levels have to be determined for all three routes (dermal, oral, inhalation), leading to testing that demands a large number of animals. On the other hand, the $3 \mathrm{R}$ principles (reduction, refinement and replacement of animal testing) shall be implemented in risk assessment according to several regulations, e.g. REACH. A reduction of animal numbers could be achieved by using route-toroute (R2R) extrapolation factor (EF) to derive the relevant route-specific noadverse-effect-level. One prerequisite for this approach is the use of scientifically sound extrapolation factors, which are based on a high quality and broad data basis (Schroeder et al., 2014). It is meritable to accumulate and manage sufficient chemical information and toxicity from experiment and, if not possible, predicted-evaluation results. The prediction of toxicity and harmfulness are known as very important, for its cost-effective bene- 
fit and handling the newly designed chemicals (Cha et al., 2014). In the field of human exposure sciences, chemicalspecific exposure information is needed to assess the extent and risk of exposure and to identify important exposure sources. However, due to the large amount of available data, finding relevant exposure studies and identifying knowledge gaps is extremely time-consuming. To overcome these challenges and make scientific literature more assessable for researchers, "text mining techniques" have shown great potential. The applicability of text mining approaches to support the risk assessment process requires validation (Larsson et al., 2014). Vitamins and minerals are micronutrients, essential components of the human diet, and may have adverse effects if consumed in excessive amounts. There is also a lower level of intake below which risk of deficiency can occur, and an exposure assessment is required to identify the correct level of supplementation to meet the needs of each age group. The daily exposure for some micronutrients shows that total intake could potentially exceed the tolerable upper intake level for various age groups. However, the intake data used in the published calculations is often old, limited to adults or by country and can be skewed to high-end-exposure. The crème global dietary exposure models are based on Monte Carlo simulations and look at the full distribution of intake for the population or subpopulation of interest. This realistic approach is common in risk analysis for food safety and accepted by regulators, but is seldom used in the field of nutritional regulation (O'Keefe \& Pigat, 2014). Suggesting that some experiments may have to be performed on some animals to explore, discover and evaluate toxicity effects of some drugs and chemicals, which may or may not lead to death therefore, animal welfare is a public good that should be protected. Consensus on how best to protect welfare and to balance it with legitimate human interests requires informed public debate. Veterinarians are uniquely placed to inform the public about the issues, and most particularly about animal's interest (Hewson, 2003).

\section{CHALLENGES TO TOXICOLOGICAL RESEARCH}

Benchmark dose modelling is increasingly used as the preferred approach to define the point-of-departure for health risk assessment of chemicals. As data are inherently variable, there is always a risk to select a model that defines a lower confidence bound contrary to expected. Nonsigmoidal model should be used with caution as it may underestimate the risk (Oberg et al., 2014a). Therefore, there is need for revision of the current doseresponse model selection paradigm, e. g. as expressed in the expert opinion from European Food Safety Agency (EFSA) and in the current modelling software in which dose-response/effect models are selected based on principle of Ocham's razor (Oberg et al., 2014b). In the European Union, under REACH regulation, companies are faced with the need to phase out chemicals of very high concern and are challenged to identify and demonstrate the safety of chemical alternatives. These substances are mainly identified by their harmonised classification and labelling according to the CLP regulation based on their intrinsic hazard properties. Green Screen ${ }^{\circledR}$ for safer chemicals is proposed as a tool that can help companies assess and avoid chemicals of high concern under REACH. In the United States, leading companies, driven by the desire to 
be competitive and stay ahead of future regulations, are using Green Screen ${ }^{\circledR}$. In the EU, the method is included in aspect of the training programme offered by SUBSUPPORT Project. Although Green Screen ${ }^{\circledR}$ is freely available, technical expertise is required to complete its assessment (Zachary et al., 2014). In Europe, scientific and public demand has driven development of regulatory in vitro assays across a range of disciplines (Akhurst et al., 2014).

In conclusion, since the results from in vitro assay cannot give true reflection of in vivo parameters, the rule of thumb is the use of animals for toxicity studies. This can be complemented by other methods aimed at encouraging replacement, refinement and reduction.

\section{REFERENCES}

Ahmed, M., 2008. Isolation, characterization and possible biocontrol application of Bdellovibrionaceae (BD) isolated from New Zealand Sources. PhD Thesis, Massey University, New Zealand.

Akhila, J. S., S. Deepa \& M. C. Alwar, 2007. Acute toxicity studies and determination of median lethal dose. Current Science, 93, 917-920.

Akhurst, L., J. Carter, B. Burlonson \& M. Chapman, 2014. Development of regulatory in vitro models. Toxicology Letters, 299S, S40-S252.

Ameni, A., A. Latorre, L. Torres \& S. Gorniak, 2014. Risk assessment of medicinal plants Caseria Sylvestris Sw (Salicaceae). Toxicology Letters, 299S, S40-S252.

Araujo, A. M., M. Valente, D. D. da Silva, M. Carvalho, F. Carvalho, M. D. L. Bastos \& P. G. de Pisho, 2014. Smart but not safe: The potential hepatoloxicity of synthetic cathimones. Toxicology Letters, 299S, S64.
Armitage, P. \& R. Doll, 1961. Stochastic models for carcinogenesis. In: Proceedings of the Fourth Berkeley Symposium on Mathematical Statistics and Probability, University of California Press, Berkeley CA, 4, 1938.

Asiedu-Gyekye, I. J., 2014. Toxicological study of new molecules in treating raw water to make it possible. Journal of Clinical Toxicology, 4, 49.

ASTM, 1987. Standard Test Method for Estimating Acute Oral Toxicity in Rats. American Society for Testing and Materials, Philadelphia P.A, USA.

Azevedo, R., V. M. Costa, D. Barbosa, A. Gomes, I. Pita, A. Sequeira, F. Pereira, M. J. A. Duarte-Araujo Duarte, E. Fernandes, M. L. Bastos, F. Carvalho \& J. Capela, 2014. Aged rats are more prone to "ectasy" neurotoxicity than adolescent rats. Toxicology Letters, 299S, S241.

Barnes, D. G. \& M. Dourson, 1988. Reference dose $(\mathrm{R} \& \mathrm{D})$ : Description and use in health risk assessment. Regulatory Toxicology \& Pharmacology, 8, 471-486.

Bender, A., 2014. Toxicity prediction using heterogenous biochemical and biological data sources. Toxicology Letters, 299S, S4.

Benigni, R. \& J. de Knecht, 2014. The future of the QSAR Toobox: Moving to less uncertainty in predictive toxicology. Toxicology Letters, 229S, S7.

Berg, E., M. Polokoff, A. O'Mahony \& J. Yang, 2014. Elucidating adverse outcome pathways with phenotypic data from primary human cell system. Toxicology Letters, 299S, S55.

Booth, A., R. J. Ameh, M. Scott \& F L. Greenway, 2010. Oral dose-ranging developmental toxicity study of an herbal supplement (NT) and garlic acid in rats. $A d-$ vanced Therapy, 27, 250-255.

Borzelleca, J. F., 1999. Profiles in toxicology, Paracelsus: Herald of modern toxicology. Toxicological Sciences, 53, 2-4. 
Botham, P. A., 2003. Acute systemic toxicity prospects for tiered testing strategies. Toxicology In Vitro, 18, 227-230.

Bower, N., 2014. Alternative mouse models for future cancer risk assessment. The Journal of Toxicological Sciences, 39, S171.

Buckley, N., 2014. Snakebite and Spider bite Clinical Management Guidelines 2013, $3^{\text {rd }}$ edn, Ministry of Health, Sydney, Australia, p. 49.

Burden, N., C. Matrony, B. P. Muller, C. Terry, C. Westmireland \& I. Kimber, 2015. Aligning the 3 Rs with new paradigms in the safety assessment of chemicals. Toxicology, 330, 62-66.

Camberos, E. P., 2014. Toxicity of fermented Jatropha curcas seed cake. Journal of Clinical Toxicology, 4, 111.

Cao, H., S. Hou, S. He, L. Lu \& X. Yang, 2014. Identification of a Bacteriovorax sp. isolate as a potential bio-control bacterium against snake head fish-pathogenic Aeromonas veronii. Journal of Fish Diseases, 37, 283-289.

Carter, A., 1980. Using the spearman-Karber method to estimate the $\mathrm{ED}_{50}$. SAS Institute Inc. pp. 1120-1125.

Castleman, M., 2002. The New Healing Herbs: The Ultimate Guide to Nature's Best Medicines, Featuring the Top 100 TimeTested Herbs, Bantam Mass Market edn, New York, USA pp. 684.

Cha, J. Y., S. Shin, K.-Y. Kim \& K. T. No, 2014. System development for toxicity evaluation and alternative suggestion of harmful chemicals to support regional all on registration and assessment of chemicals. Toxicology Letters, 299S, S40-S52.

Ciftci, A., E. E. Onuk, G. Ciftci, A. Findik, M. U. Sogut, B. I. Didinen, A. Aksoy, K. Ustunakin, T. Gulhan, F. Balta \& S. Altun, 2016. Development and validation of glycoprotein-based native-submit vaccine for fish against Aeromonas hydrophila. Journal of Fish Diseases, DOI:10.111/jfd. 12499 .
CIOMS, 1985. International Guiding Principles for Biomedical Research Involving Animals c/o WHO 121, Geneva, p. 9.

Cook, G. C. \& A. Zumila, 2009. Manson's Tropical Diseases, Saunders Elsevier Ltd. China p. 1830

Cormier, J. \& M. Janes, 2016. Concentration and detection of hepatitis A virus and its indicator from artificial seawater using zeolite. Journal of Virological Methods, 235, 1-8.

Curren, R. D. \& J. W. Harbell, 1998. In vitro alternatives for ocular irritation. Environmental Health Perspective, 106, 485-492.

Dach, K., H. Alon, S. Giersiefer \& E. Fritsche, 2014. Of mice and men: Mechanistic studies on the developmental neurotoxicity of polybrominated diphenyl esthers (PBDES) in a 3D in vitro model. Toxicology Letters, 299S, S118.

Deavall, D., R. Roberta \& R. Knight, 2014. The impact of clinical data from nonrodent species in the risk assessment of anticancer small molecule drugs. Toxicology Letters, 299S, S40-S252.

Deschamps, F. J., 2014. A new challenge: Assessment of metal prosthesis intoxication. Journal of Clinical Toxicology, 4, 72.

De Sosa, C. A., 1992. Famous names in toxicology: Mateo Orfila (1787-1853). Adverse Drug Reactions and Toxicological Reviews, 11, 69-70.

Dixon, W. J. 1991. Staircass boassay: The upand-down method. Neuroscience and Biobehavioural Reviews, 15, 47-50.

Dreisbach, R. H. \& W. O. Robertson, 1987. Alcohol and glycols. In: A Handbook of Poisoning: Prevention, Diagnosis and Treatment, Appleton and Large, London, p. 176.

Duncan, I. J. H. \& D. Fraser, 1997. Understanding. In: Animal Welfare, eds M. A. Appleby \& B. O. Hughes, Wallong Fund, CABI publication, UK.

Eastmond, D. A., A. Hartwig, D. Anderson, W. A. Anwarb, M. C. Cimino \& I. Dobrev, 2009. Mutagenicity testing for chemical 
risk assessment. Update of the WHO/IPCS Harmonized Scheme, Mutagenesis, 24, 341-349.

Faccioli, L. H., 2014. Tityus serrulatus venom induces inflammation by mechanism dependent on lipid mediator release and lipid bodies' formation. Journal of Clinical Toxicology, 4, 102.

Fenton, G. C., D. M. Malliday, R. Mason \& C. W. Stevenson, 2014. Medial prefontal cortex circuit function during retrieval and extinction of associative learning under anaesthesia. Neuroscience, 265, 204-216.

Forni, C., 2014. Pollutants toxicity towards aquatic macrophytes. Journal of Clinical Toxicology, 4, 71 .

Gant, T. W., 2015. Advancing scientific innovation towards improving public health. Toxicology Letters, 229S, S2.

Ganiger, S., H. N. Malleshapa, H. Krishnappa, G. Rajashekhar, V. R. Rao \& F. A. Sullivan, 2009. A two generation reproductive toxicity study with curcumin, turmeric yellow in Wistar rats. Food and Chemical Toxicology, 45, 64-69.

Garg, S. K., 2004. Veterinary Toxicology, CBS Publishers and Distributors, New Delhi, India, p. 321.

Gholami, S., F. Soleimani, F. H. Shirazi, M. Toahidpour \& M. Mahmoudian, 2010. Evaluation of mutagenicity of mebudipine, a new calcium channel blocker. Iranian Journal of Pharmaceutical Research, 9, 49-53.

Gikermann-Haerter, K. \& M. A. Moskowitz, 2008. Animal models of migraine headache and aura. Current Opinion in Neurology, 21, 294-300.

Goddard, M., D. K. Krewski, J. Zielinski \& M. A. Ritter, 1996. Toxicological risk assessment. In: Elemental Toxicology, UK.

Golberg, L., 1983. Structure-activity correlation as a predictive tool in toxicological study. In: Fundamentals, Methods and Application, Hemisphere, Washington USA.

Gordon, I., M. Paoloni, C. Mazdco \& C. Khanna, 2009. The comparative oncology trials consortium: Using Spontaneously occurring cancers in dogs to inform the cancer drug development pathway. PLoS Medicine, 6, doi:10.1371/journalpubmed. 10000161

Greco, R., A. S. Mangione, G. Sandrini, G. Nappi \& C. Tassorelly, 2014. Activation of $\mathrm{CB}_{2}$ receptors as potential therapeutic target for migraine: Evaluation in animal model. The Journal of Headache and Pain, 15, 1-8.

Gribaldo, L., A. Gennari, K. Blackburn, C. Cleondson, A. Deguercy, A. Meneguz, W. Pfaller \& I. Ruhdel, 2005. Acute Toxicity in Alternative (Non-Animal) Methods for Cosmetics Testing: Current Status and Future Prospects. eds C. Eskes \& V. Zuang, ATLA, 33, Suppl. 1, 27-34.

Hamburger, F., 1989. In vivo testing in the study of toxicity and safety evaluation. In: $A$ Guide to General Toxicity, $2^{\text {nd }}$ edn, ed J. K. Marquis, Karger, New York, p. 18.

Hastings, K. L., 2014. Phospholipodosis: Histologic finding or histopathology? The Journal of Toxicological Sciences, 39, S17EL6.

Hew, K. W., 2014. Issues and challenges in reproductive toxicity testing, including juvenile animal studies. The Journal of Toxicological Sciences, 39, S17.

Hewson, C. J., 2003. What is animal welfare? Common definitions and their practical consequences. Canadian Veterinary Journal, 44, 496-499.

Hofmann, T., G. Horstmann \& I. Stammberger, 2002. Evaluation of the reproductive toxicity and embryotoxicity of insulin glargine (lantus) in rats and rabbits. International Journal of Toxicology, 21, 181189.

Howe, R. B., K. S. Crump \& C. van Landingham, 1986. GLOBAL1986. A computer program to extrapolate quantal animal toxicity data to low doses. K. S. Crump \& Co, Ruston.

Hundal, S. S., 2014. Environmental contaminants and reproductive abnormalities - a 
perspective. Journal of Clinical Toxicology, 4, 75

Ibiam, U. A., O. U. Orji \& C. J. Chukwu, 2014. GC-MS analysis of leaf powder of Psychotria microphylla and its acute toxicity on Clarias gariepinus juveniles. Journal of Clinical Toxicology, 4, 77.

Jaijoy, K., N. Svonthornchareonnon, N. Lertprasertsuke, A. Panthong \& S. Sireeratawong, 2010. Acute and chronic oral toxicity of standardized water extract from the fruit of Phyllanthus emblica Linn. International Journal of Applied Research and Natural Product, 3, 48-58.

Jennen, D., J. Polman, J. Van Delft, E. Van Someren, R. Stieum, D, Kroese, G. Montoya-Parra \& H. Kamp, 2014. Data integration of endpoints, chemoinformatics and omics. Toxicology Letters, 229S, S4S21.

Jennison, C. \& B. W. Turnbull, 2000. Group Sequential Methods with Applications to Clinical Trials. Chapman and Hall, CRC Boca Raton, FL.

Kararli, T. T., 1995. Comparison of the gastrointestinal anatomy, physiology, and biochemistry of humans and commonly used laboratory animals. Biopharmacotics and Drug Disposition, 16, 351-380.

Karber, G. 1931. Reihenversucbe. Archives of Experimental Pathology and Pharmacology 162, 480-483.

Kavanagh, S., H. Mellor, C. Pollard, S. Robinson, S. Platz \& R. Roberts, 2014. Reducing attrition in drug development: Smart leading pre-clinical safety assessment. Toxicology Letters, 299S, S167.

Kimm-Brinson, K. \& J. S. Ramsdell, 2001. The red tide toxin, brevetoxin, induces embryo toxicity and developmental abnormalities. Environmental Health and Perspectives, 109, 377-381.

Kothari, N., S. Kothari, Y. J. Choi, A. Dey, D. E. Briles, D. K. Rhee \& R. Carbis, 2015. A bivalent conjugate vaccine containing $\mathrm{P}_{\mathrm{S}} \mathrm{P}_{\mathrm{A}}$ families 1 and 2 has the potential to protect against a wide range of Streptococ- cus pneumonia strains and Salmonella typhi. Vaccine, 33, 783-788.

Krewski, D. \& C. Brown, 1981. Carcinogenic risk assessment: A guide to the literature. Biometrics, 37, 6-10.

Kue, C. S., K. Y. Tan, M. L. Lam \& H. B. Lee, 2015. Chick embryo chorioallantoic membrane (CAM). An alternative predictive model in acute toxicological studies for anticancer. Experimental Animals, 64, 128-138.

Lalloo, D. G., A. J. Trevett, \& A. Saweri, S. Naragi, R. D. G. Theakston \& D. A. Warrell, 1995. The epidemiology of snake bite in Central Province and National Capital District, Papua, New Guinea. Trans. Royal Society of Tropical Medicine \& Hygiene, 89, 178-182.

Larsson, K., I. Silins, Y. Guo, A. Korhomen, U. Stenius \& M. Berghind, 2014. Text mining for improved human exposure assessment. Toxicology Letters, 299S, S40 S252.

Lawrence, R., D. Coleman \& D. Mitchell, 2014. Further progress on steps to reduce animal numbers on regulatory toxicology studies utilizing microsampling and sampling sparning techniques. Toxicology Letters, 299S, S223.

Lee, J. M., D. Kim, Y. H. Lee, S. H. Park, H. Y. Lee, M. Y. Lee, B. S. Hai, M. Known, W. C. Sohn, J. H. Seok, J. K. Lee, J. Y. Jeong, J. S. Kang \& J. Kang, 2014. 90-day repeated dose toxicity and genotoxicity tests of Ivodia officinalis. The Journal of Toxicological Sciences, 39, S357. P229.

Lees, D., S. Horner, S. Robinson, D. Ryan, R. Callander \& R. Roberts, 2014. Target organ toxicities in studies conducted to support first time in man dosing: An analysis across species and therapy areas. Toxicology Letters, 299S, S237.

Litchfield, J. T. \& F.A. Wilcoxon, 1949. A simplified method of evaluating doseeffect experiments. Pharmacology and Experimental Therapeutics, 96, 99-113. 
Litt, J. Z., 2015. Litt's Drug Eruption and Reaction Manual, $21^{\text {st }}$ edn, CRC Press, Tailor and Francis, Boca Raton, p. 499.

Lorke, D., 1983. A new approach to practical acute toxicity testing. Archives of Toxicology 53, 275-289.

Mahajan, A., \& S. Dua, 1994. Comparison of processing treatments on the composition and functional properties of rapeseed preparations (Brassica campestris L. var. toria). Food, 38, 578-587.

Makin, A., M. L. Jensen \& J. Logsted, 2014. Dermal dosing studies in juvenile minipigs. The Journal of Toxicological Sciences, 39, S302.

Matsuura, I., T. Sailt, E. Tani, Y. Wako, H. Iwata \& N. Toyota, 2005. Evaluation of a two-generation reproduction toxicity study adding endpoints to detect endocrine distrupting activity using lindane. Journal of Toxicological Science, 30, 135-161.

Miller, L. C. \& M. L. Tainter, 1944. Examination of $\mathrm{LD}_{50}$ and $\mathrm{ED}_{50}$ values and errors using logarithm probity paper. Proceedings of the Society of Experimental Biology \& Medicine, 57, 261-264.

Moxon, E. R., 1990. A Cancer Review: Modern Vaccines, Current Practice and New Approaches, Edward Arnold, A Division of Hodder R. Stoughton, Londn

Munn, S., 2014. Low dose effects: The wider consequences for risk assessment. Toxicology Letters, 299S, S22-S29.

Muralidhara, S., R. Ramanathan, S. M. Mehta, L. H. Lash, D. Acosta, \& J. V. Bruckner, 2010. Acute and chronic oral toxicity of standardized water extract from the fruit of phyllanthus emblica Linn. International Journal of Applied Research and Natural Products, 3, 48-58.

NIEHS, 2000. National Toxicology Research Program: Notice of Peer Review Meeting on the Revised Up-and-Down Procedure (UDP) as an Alternative Test Method for Assessing Acute Oral Toxicity. Request for Comments 65 FR 35109 June 1, 2000.

O'Keefe, L. \& S. Pigat, 2014. Micronutrient exposure modelling: To build a refined safety assessment for micronutrients. Toxicology Letters, 299S, S40-S252.

Oberg, M., J. Reingblom \& G. Johnson, 2014a. Current modelling practice may lead to falsely high benchmark dose estimates. Toxicology Letters, 299S, S123.

Oberg, M., E. Tornquist, A. Annas, B. Granath, E. Jalkesten \& I. Cotgreave, 2014b. Strategic focus on 3R principles reveals major reductions in the use of animals in pharmaceutical toxicity testing. Toxicology Letters, 299S, S86.

Odessa, I. C., 2014. Method for treating venomous bites and snakes. United States Patent Application Publication: US2014/0087003A1.

OECD, 1987. Guideline for the Testing of Chemicals. Testing Guideline 401, Acute Oral Toxicity. OECD Paris. https://ntp. niehs.nih.gov/iccvam/docs/acutetox_docs/ udpproc/udpfin01/append/appi.pdf (12 July 2016 date last accessed).

OECD, 2000a. Guideline Document on Acute Oral Toxicity Testing. Environmental Health and Safety Monograph Series on Testing and Assessment No. 24.

OECD, 2000b. Guideline Document on the Recognition Assessment and Use of Clinical Signs as Human Endpoints for Experimental Animals used in Safety Evaluation. Environmental Health and Safety Monograph Series on Testing and Assessment No. 19.

OECD, 2001a. Test Guideline 420. Acute Oral Toxicity - Fixed Dose Procedure.

OECD, 2001b. Test Guideline 423. Acute Oral Toxicity - Acute Toxic Class Method.

OECD, 2001c. Test Guideline 425. Acute Oral Toxicity - Up-and-Down Procedure.

OECD, 2010. Test Guideline 417: Toxicokinetics, Organisation for Economic Cooperation and Development, Paris. Adopted 22 July, 2010.

OECD, 2015a. Test Guideline 421: Reproduction/Developmental Toxicity Screening Test. Adopted 28 July, 2015. 
OECD, 2015b. Test Guideline 422: Combined Repeated Dose Toxicity Study with the Reproduction/Developmental Toxicity Screening Test. Adopted 28 July, 2015.

Oliveira, C. D., S. Q. Moreira, I. L. R. Marques de Sa, S. Hde \& M. Yonamine, 2010. Maternal and developmental toxicity of ayahusea in Wistar rats. Birth Defects Research. Part B, Developmental \& Reproductive Toxicology, 89, 207-212.

Oliveira, P. F., J. L. Damasceno, C. S. Bertanha, A. R. B. Araujo, P.-M. Pauletti \& D. C. Taveres, 2014. Analysis of in vitro antitumor activities of Styrax camporum extract and its chemical markers, egonol and homegonol. Journal of Clinical Toxicology, 4, 113.

Parasuraman, S. 2011. Toxicological screening. Journal of Pharmacology and Pharmacotherapeutics, 2, 74-79.

Parra, G. A. M., V. Strauss, E. Fabian, H. Kamp, W. Mellert, T. Walk, R. Losser, M. Herold, G. Krennrich, E. Peter \& B. Van Ravenzway, 2014. Qualitative and quantitative comparison of toxicological properties of racemates and their enantumers with metabolomics. Toxicology Letters, 299S, S282.

Peshin, S. S., A. Srivastara \& Gupta, 2014. Poisoning in children: A poisoning helpline experience. Journal of Clinical Toxicology, 4, 51.

Piao, Z., Y. Akeda, D. Takeuchi, K. J. Ishii, K. Ubukata, D. E. Briles, K. Tomono \& K. Oishi, 2014. Protective properties of a fusion pneumococcal surface protemA $\mathrm{P}_{\mathrm{S}} \mathrm{P}_{\mathrm{A}}$ vaccine against pneumococcal challenge by five different $\mathrm{P}_{\mathrm{S}} \mathrm{P}_{\mathrm{A}}$ clades in mice. Vaccine, 32, 5607-5613.

Piersma, A., 2014. Low-dose effects: Experimental challenges for endocrine disruption. Toxicology Letters, 299S, S37.

Radenkova-Saeva, J., 2008. Historical development of toxicology. Acta Medica Bulgarica, 35, 47-52.

Reed, L. J., \& H. Muench, 1938. A simple method of estimating fifty percent end- points. American Journal of Hygiene, 27, 493-497.

Robinson, S. \& K. Chapman, 2009. Are acute toxicity studies required to support overdose for new medicines? Regulatory Toxicology \& Pharmacology, 55, 110.

Rosenkranz, H. S., N. Takihi \& G. Klopman, 1999. Structure activity-based predictive toxicology: an efficient and economical method for generating non-cosmetics data bases. Mutagenesis, 6, 391-394.

Ruzyn, I., 2014. Toxicogenomics and toxicogenetics: Genetic diversity and susceptibility to toxicity in next-generation human health risk assessment. The Journal of Clinical Toxicology, 39, S16.

Saganuwan, S. A., V. M. Ahur \& C. A. Yohanna, 2008. Acute toxicity studies of potassium permanganate in Swiss albino mice. Nigeria Journal of Physiological Sciences, 23, 31-35.

Saganuwan, S. A., 2009. Tropical plants with antihypertensive, antiasthmatic and antidiabetic value. Journal of Herbs, Spices and Medicinal Plants, 15, 24-44.

Saganuwan, S. A., 2011. A modified arithmetical method of Reed and Munch for determination of a relatively ideal median lethal dose $\left(\mathrm{LD}_{50}\right)$. African Journal of Pharmacy and Pharmacology, 5, 15431546.

Saganuwan, S. A., P. A. Onyeyili \& A. O. Suleiman, 2011. Comparative toxicological effects of orally and intraperitoneally administered aqueous extract of Abrus precatorius leaf in Mus musculus. Herba Polonica, 57, 34-44.

Saganuwan, S. A., 2012. Principles of Pharmacological Calculation, $1^{\text {st }}$ edn, Ahmadu Bello University Press, Zaria, pp. 529.

Saganuwan, S. A., 2014. Arithmetic method of rough estimation of median lethal dose $\left(\mathrm{LD}_{50}\right)$ using up-and-down procedure. Toxicology Letters, 229S, S127.

Saganuwan, S. A. \& P. A. Onyeyili, 2016. The paradox of human equivalent dose formula: A canonical case study of Abrus 
precatorius aqueous leaf extract in monogastric animals. Macedonian Veterinary Review, 39, 23-32.

Saganuwan, S. A., 2016. The new algorithm of median lethal dose $\left(\mathrm{LD}_{50}\right)$ and effective dose fifty $\left(\mathrm{ED}_{50}\right)$ of Micrarus fulvius venom and antivenom using mice. FASEB Journal 30, Supplement 16501.

Sanchez, E. E., D. Hotle \& A. RodriquezAcosta, 2003. Neutralization of Bitis parviocula (Ethiopian mountain adder) venom by the South African Institute of Medical Research (SAIMR) antivenom. The Revista do Instituto de Medicina Tropical de São Paulo, 53, 213-217.

Savolainen, K., 2014. New risk assessment concept for engineered nanomaterials required. Toxicology Letters, 299S, S12.

Sawai, Y., M. Makino \& Y. Rawa-Mura, 1976. Epidemiological study of Habu bites on the Amani and Okinawa Islands of Japan. In: Plant, Animal and Microbial Toxins, vol. 2, eds A. Obsaka, K. Hayashi \& Y. Sawai, Plenum Press, New York, pp. 439-450.

Schroeder, K., S. Hoffmann-Duert, L. Mangelsdorf \& S. Escher, 2014. Route to route extrapolation factors for regulatory risk assessment - A probabilistic approach. Toxicology Letters, 299S, S40S52.

Sewell, F. \& K. Chapman, 2014. Global crosscompany data-sharing on the use of recovery animals for human safety assessment. Toxicology Letters, 299S, S113-S114.

Shairr, A., J. Milgram \& R. Shahar, 2006. Structural and functional anatomy of the neck musculature of the dog (Canis familiaris). Journal of Anatomy, 208, 331-351.

Shiryaev, A. N. \& V. G. Spokoing 2000. Statistical Experiments and Decisions. Statistical Inference for Autoregressive Models of the First Order Asymptomtic Theory. World Scientific Publication, London, pp. 5-8.

Stallard, N. \& A. Whitehead, 1995. Reducing animal numbers in the fixed dose proce- dure. Human and Experimental Toxicology, 14, 315-323.

Stirling, D. A., 2006. History of toxicology and allied sciences: A bibliographic review and guide to suggested readings. International Journal of Toxicology, 25, 261-268.

Stitzel, K., 2000. Overview of Test Guidelines 425, Up-and-Down Procedure. Up-andDown Procedure Peers Panel Report, The Procters and Gamble Company, pp. J15J17.

Stolley, P. D., 1995. Investigating Disease Patterns: The Science of Epidemiology, Scientific American library, New York, USA pp. 242.

Tavares, D. C., P. F. de Oliveira, J. L. Damasceno, H. D. Nicollela, C. S. Bertanha, A. R.B . Arauja \& P.M. Pauletti, 2014. Toxicogenetic evaluation of Styrax camporum extract, lignans, egonol and homoegonol using the comet and micronucleus assays. Journal of Clinical Toxicology, 4, 112.

Travis, C. C. \& R. K. White, 1988. Interspecies scaling of toxicity data. Risk Analysis, $8,119-125$.

Trevan, J. W., 1927. The error of determination of toxicity. Proceedings of the Royal Society of London, Series B 101, 483-514.

Tsai, C. S. J., 2014. Nanoparticle exposure assessment, dose metric and controls. Journal of Clinical Toxicology, 4, 103.

Tsatsakis, A., J. C. Lamb \& D. Schrenk, 2014. Are non-monotonic dose-responses at low dose levels toxicologically relevant? Toxicology Letters, 229S, S2-S3.

Ufot, S., F. E. Uboh, E. U. Eyong \& P. E. Ebong, 2014. Assessment of the litter size, birth weight and serum sex hormonal profile of rats orally exposed to crude oil. Journal of Clinical Toxicology, 4, 84.

UNECE, 2003. Globally Harmonized System of Classification and Labelling of Chemicals (6HS), New York and Geneva, United Nations 2003.

Uyama, Y., 2015. Roles of regulatory science on review and safety assessment of new drugs. In: Proceedings of the $88^{\text {th }}$ Annual 
Meeting of the Japanese Pharmacological Society for the Next Innovation in Medical Science and Technology, Nagoya Congress Centre, March 18-20 2015, pp. 3-4.

Vale, A., 2014. Toxicology: Past successes, present realities and future challenges. Toxicology Letters, 292S, S2.

Van Delft, J. H. L., E. van Agen, S.G. van Breda, M. H. Herwijnen, Y. C. Staal \& J. C. Kleinjans, 2004. Discrimination of genotoxic from non-genotoxic carcinogens by gene-expression profiling. Carcinogenesis, 25, 1265-1276.

Van Der Laan, J.-W., 2014. Current topics on nonclinical safety assessment of human pharmaceuticals from a European perspective. The Journal of Toxicological Sciences, 39, 89 .

Van Der Laan, J.-W., S. Gould \& J. Y. Tanir, 2014a. Nonclinical evaluation of adjuvants and adjuvant vaccines. Background of the WHO guideline. The Journal of Toxicological Sciences, 39, S51.

Van Der Laan J.-W., P. T. Theunissen, A. H. Piersma, J. Stewart, A. Hoberman, G. Cappon \& Chen, C. 2014b. A comprehensive data survey of the relative value of rat versus rabbit developmental toxicity data in the risk assessment for pharmaceuticals. The Journal of Toxicological Sciences, 39. S185.

Van Der Heuvel, M. J., D. G. Clark, R. J. Fielder, P. P. Koundakjian, G. J. A. Olivier, D. Pelling, N. J. Tomlinson \& P. A. Walker, 1990. The international validation of a fixed-dose procedure as an alternative to the classical $\mathrm{LD}_{50}$ test. Food and Chemical Toxicology, 28, 469-482.

Vicario, L., J. Dixon, M. Rattray, E. Barnes, J. Wright \& M. Dixon, 2014. Evaluating developmental toxicity in the rat as a basis for human risk assessment for cleft palate. Toxicology Letters, 299S, S120.

Warrell, D. A., 2004. Epidemiology, clinical features and management of snakebites in Central and South America. In: Venomous Reptiles of the Western Hemisphere, eds J.
Campbell \& W. W. Lamar, Cornell University Press, Ithaca, pp. 709-761.

Warrell, D. A., 2005. Treatments of bites by adders and exotic venomous snakes. British Medical Journal, 331, 1244-1247.

Warrell, D. A. \& C. Amett, 1976. The importance of bites by the saw-scaled or carpet viper (Echis carinatus). Epidemiological studies in Nigeria and a review of the world literature. Acta Tropica, 33, 307341.

Watson, S. B., B. Brownlee, T. Satchwili \& E. Hargesheimer, 2000. Quantitative analysis of trace levels of geosmin and MIB in source and drinking water using headspace SPME. Water Research, 39, 4899-4912.

Weinbauer, G. F. 2014. The 3R concept and DART evaluation in nonhuman primates an appraisal. The Journal of Toxicological Sciences, 39, S186, W7.2.

Wen, C., M. Xue, H. Liang \& S. Zhou, 2014. Evaluating the potential of marine. Bacteriovorax $\mathrm{sp.}$ DA5 as a biocontrol agent against vibriosis in Litopenaeus vannamei larvae. Veterinary Microbiology, 173, 8491

WHO, 2008. Skin Sensitization in Chemical Risk Assessment. Publication of World Health Organization Bulletin, Geneva.

Wolf, R., N. Scheer \& C. Henderson, 2014. The application of transgenic animal models to elucidate human pathways of drug metabolism and chemical toxicity. Toxicology Letters, 229S, S2.

Yamada, T., Y. Tanaka, R. Hasegawa, Y. Sakuratani, Y. Yamazoe, A. Ono, A. Hirose \& M. Hayashi, 2014. Hazard evaluation support (HESS): Category approach to screen chemicals, which are metabolized to methoxy-orethoxyacetic acid responsible for testicular toxicity. Toxicology Letters, 299S, S40-S252.

Yamashita, A., 2015. Zebrafish: as a model animal for toxicity evaluation in drug discovery. In: Proceeding of the $88^{\text {th }}$ Annual Meeting of the Japanese Pharmacological Society for the Next Innovation in Medical 
Toxicity studies of drugs and chemicals in animals: An overview

Science and Technology, Nagoya Congress, Centre, March 18-20, 2015.

Yoon, M., J. Pedersen, E. LeChyse, M. Andersen \& H. Clewell, 2014. Liver bioreactor as an in vitro metabolism system for quantitative in vitro to in vivo extrapolation. Toxicology Letters, 299S, S13.

York, M. \& W. A. Steilling, 1998. A critical review of the assessment eye irritation potential using the Draize rabbit eye test. Journal of Applied Toxicology, 18, 223 240.

Zachary, M., A. M. Gechart \& M. Whittaker, 2014. Green Screen ${ }^{\circledR}$ for safer chemicals, as a support tool for the EU reach regulation. Identifying chemicals of very high concerns (SVHC) and safer alternatives. Toxicology Letters, 299S, S40-S52.

Zhang, Q., S. X. Zeng \& H. Lu, 2015. Determination of maximum tolerated dose and toxicity of Inauhzin in mice. Toxicology Reports, 2, 546-554.

Paper received 10.12.2015; accepted for publication 26.02.2016

\section{Correspondence:}

\section{S. A. Saganuwan}

Department of Veterinary Physiology,

Pharmacology and Biochemistry,

College of Veterinary Medicine,

University of Agriculture,

P.M.B. 2373, Makurdi,

Benue State, Nigeria

tel: $+2348027444269,+2347039309400$

e-mail: pharn_saga2006@yahoo.com 